\title{
Antifungal efficacy of octylgallate and 4-isopropyl-3- methylphenol for control of Aspergillus
}

\author{
Jong H. Kim", William Hart-Cooper², Kathleen L. Chan'1, Luisa W. Cheng ${ }^{1}$, William J. Orts² and Kaj Johnson ${ }^{3}$
}

*Correspondence: jongheon.kim@ars.usda.gov

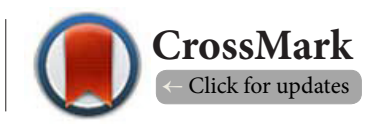

'Foodborne Toxin Detection and Prevention Research Unit, Western Regional Research Center, USDA-ARS, 800 Buchanan St., Albany, CA 94710, USA.

2Bioproducts Research Unit, Western Regional Research Center, USDA-ARS, 800 Buchanan St., Albany, CA 94710, USA.

${ }^{3}$ People Against Dirty, Inc., 637 Commercial St., San Francisco, CA 94111, USA.

\begin{abstract}
Background: Control of fungi is problematic, since effective methods for intervening fungal infection or contamination, especially for those resistant to drugs/fungicides, are often very limited. Generally regarded as safe (GRAS) agents, such as natural compounds or their structural analogs could be potential sources of sustainable antifungal agents. As a proof of concept, antifungal efficacy of twenty-one compounds (mostly GRAS) and six conventional preservatives was investigated against Aspergillus brasiliensis, one of the challenge microbes for preservative evaluation. In particular, efficacy of octylgallate (OG) and 4-isopropyl3-methylphenol (4I3M) was evaluated for synergism as well as for overcoming fludioxonil (phenylpyrrole fungicide) tolerance of Aspergillus mutants.

Findings: Out of twenty-one compounds examined (Clinical Laboratory Standards Institute Protocol), five compounds showed the highest antifungal activity, viz., OG $>$ benzaldehyde $>$ nonylgallate $>$ 2-hydroxy-4-methylbenzaldehyde > carvacrol (higher to lower activity), where OG and benzaldehyde exhibited fungicidality. For formulation purpose, synergism was further investigated between OG (showing the highest activity) and conventional preservatives. 4I3M was the most responsive preservative to OG, where antifungal efficacy of 4I3M was augmented four-fold with $\mathrm{OG}+4 \mathrm{I} 3 \mathrm{M}$ combination. Model yeast bioassay showed vacuolar and antioxidant mutants were highly susceptible to 4I3M. 4I3M further overcame fludioxonil tolerance of oxidative signaling mutants of Aspergillus. Of note, while 4I3M and its natural derivatives (thymol, carvacrol) were compatible with two out of three commercial surfactants explored, the remaining surfactant antagonized antifungal activity of 4I3M and its derivatives.

Conclusions: OG (GRAS agent) and 4I3M (conventional preservative), alone or in combination, effectively prevented fungal growth, where vacuolar detoxification and/or antioxidant system were important for fungal survival against 4I3M. While 4I3M overcame fludioxonil tolerance of Aspergillus mutants, types of surfactants co-applied were crucial for achieving optimum activity of antifungal compounds. Accordingly, comprehensive characterization of compound-compound or compound-surfactant specificity would be required further when developing sustainable antifungals.
\end{abstract}

Keywords: Antifungal, Aspergillus, fludioxonil resistance, 4-Isopropyl-3-methylphenol, octylgallate, surfactant compatibility, sustainability, yeast

\section{Background}

Filamentous fungi in the genus Aspergillus are opportunistic pathogens and/or producers of hepato-carcinogenic mycotoxins, which cause serious human health risks [1,2]. Among those, Aspergillus brasiliensis, a member of the black aspergilli, has recently been identified as a causative agent of keratitis [3]. A. brasiliensis is one of the challenge microorganisms for evaluating preservative efficacy in industrial products, by tracking decreases in microbial populations [4].

There are increasing demands for safe, sustainable pre- 
Kim et al. Microbiology Discovery 2016,

servatives, which present no significant human health or environmental side effects, and therefore, could avoid negative consumer perception. Many natural products are "generally regarded as safe (GRAS)" compounds, and are potential sources of antifungal agents, either in their intact structure or as lead compounds for more potent analogs [5].

Despite their utility, preservatives can be deactivated by certain components, such as surfactants, in the formula. Surfactants are widely used in household products and industrial applications [ 6 and references therein]. Although possible toxicities of surfactants to living organisms have been investigated [6], the mechanism of preservative deactivation by certain surfactants is vastly undetermined.

In this study, twenty-one compounds and six conventional preservatives were investigated for the search of sustainable alternatives to toxic, allergic preservatives. Candidate compounds, such as octylgallate (OG) or 4-isopropyl-3-methylphenol (4I3M), effectively prevented fungal growth and/or overcame fungicide tolerance with compound-compound or compound-surfactant specificity.

\section{Findings}

Antifungal synergism between $O G$ and conventional preservatives: Compound-compound specificity

Initially, antifungal efficacy of twenty-one compounds was evaluated (up to $1 \mathrm{mM}$ cut off) against $A$. brasiliensis, where OG (GRAS agent) exhibited the highest activity (See Additional File 1; Supplementary Table $\mathbf{S 1}$ for details).

For formulation purpose, levels of synergism between OG and eight compounds, viz., six conventional preservatives (Table 1) and two natural analogs of 4I3M (thymol, carvacrol), were investigated via checkerboard bioassay (Additional File 1: Methods).

For MICs, co-application of OG with six agents (four preservatives, thymol, carvacrol) resulted in augmentation of antifungal efficacy (both OG and six agents) [Fractional Inhibitory Concentration Indices $(\mathrm{FICls})=0.8$ to 1.0 ; Table 1], while that with phenoxyethanol or 2,3,4-trihydroxybenzaldehyde showed indifference $(\mathrm{FICl}=2.0)$. Of note, lowest MICs (preservatives) were achieved with $4 \mathrm{I} 3 \mathrm{M}$ (and thymol, carvacrol) $(\mathrm{MIC}=0.4 \mathrm{mM}$; Table 1), while that with other preservatives ranged 0.8 to $12.8 \mathrm{mM}$ (viz., less effective). $4 \mathrm{I} 3 \mathrm{M}$ was the most responsive preservative to

Table 1. Antifungal efficacy of combined application of OG ( $\mathrm{mM})$ with six preservatives or natural analogs of $4 \mathrm{I} 3 \mathrm{M}$ (thymol, carvacrol; $\mathrm{mM}$ ) tested against $A$. brasiliensis. *

\begin{tabular}{|c|c|c|c|c|c|c|}
\hline Compounds & $\begin{array}{l}\text { MIC } \\
\text { alone }\end{array}$ & $\begin{array}{l}\text { MIC } \\
\text { combined }\end{array}$ & FICI & $\begin{array}{l}\text { MFC } \\
\text { alone }\end{array}$ & $\begin{array}{l}\text { MFC } \\
\text { combined }\end{array}$ & FFCI \\
\hline $\begin{array}{l}\text { OG } \\
\text { Phenoxyethanol }\end{array}$ & $\begin{array}{l}0.1 \\
12.8^{\dagger}\end{array}$ & $\begin{array}{l}0.1 \\
12.8\end{array}$ & 2.0 & $\begin{array}{l}0.2 \\
12.8^{\dagger}\end{array}$ & $\begin{array}{l}0.2 \\
12.8\end{array}$ & 2.0 \\
\hline $\begin{array}{l}\text { OG } \\
\text { 2,3,4-Trihydroxy-benzaldehyde }\end{array}$ & $\begin{array}{l}0.1 \\
12.8^{\dagger}\end{array}$ & $\begin{array}{l}0.1 \\
12.8\end{array}$ & 2.0 & $\begin{array}{l}0.2 \\
12.8^{\dagger}\end{array}$ & $\begin{array}{l}0.2 \\
12.8\end{array}$ & 2.0 \\
\hline $\begin{array}{l}\text { OG } \\
\text { Caprylyl glycol }\end{array}$ & $\begin{array}{l}0.1 \\
6.4\end{array}$ & $\begin{array}{l}0.025 \\
3.2\end{array}$ & 0.8 & $\begin{array}{l}0.2 \\
12.8^{\dagger}\end{array}$ & $\begin{array}{l}0.2 \\
12.8\end{array}$ & 2.0 \\
\hline $\begin{array}{l}\text { OG } \\
\text { Caprylhydroxamic acid }\end{array}$ & $\begin{array}{l}0.1 \\
1.6\end{array}$ & $\begin{array}{l}0.025 \\
0.8\end{array}$ & 0.8 & $\begin{array}{l}0.2 \\
12.8^{+}\end{array}$ & $\begin{array}{l}0.2 \\
12.8\end{array}$ & 2.0 \\
\hline $\begin{array}{l}\text { OG } \\
\text { 4'-Hydroxyacetophenone }\end{array}$ & $\begin{array}{l}0.1 \\
12.8^{\dagger}\end{array}$ & $\begin{array}{l}0.05 \\
6.4\end{array}$ & 1.0 & $\begin{array}{l}0.2 \\
12.8^{\dagger}\end{array}$ & $\begin{array}{l}0.2 \\
12.8\end{array}$ & 2.0 \\
\hline $\begin{array}{l}\text { OG } \\
\text { 4-Isopropyl-3-methylphenol }\end{array}$ & $\begin{array}{l}0.1 \\
1.6\end{array}$ & $\begin{array}{l}0.05 \\
0.4\end{array}$ & 0.8 & $\begin{array}{l}0.2 \\
6.4\end{array}$ & $\begin{array}{l}0.2 \\
6.4\end{array}$ & 2.0 \\
\hline $\begin{array}{l}\text { OG } \\
\text { Thymol }\end{array}$ & $\begin{array}{l}0.1 \\
0.8\end{array}$ & $\begin{array}{l}0.05 \\
0.4\end{array}$ & 1.0 & $\begin{array}{l}0.2^{\ddagger} \\
1.6\end{array}$ & $\begin{array}{l}0.2 \\
1.6\end{array}$ & 2.0 \\
\hline $\begin{array}{l}\text { OG } \\
\text { Carvacrol }\end{array}$ & $\begin{array}{l}0.1 \\
0.8\end{array}$ & $\begin{array}{l}0.05 \\
0.4\end{array}$ & 1.0 & $\begin{array}{l}0.2 \\
6.4\end{array}$ & $\begin{array}{l}0.2 \\
6.4\end{array}$ & 2.0 \\
\hline $\begin{array}{l}\text { Mean: } \\
\text { OG } \\
\text { Preservatives \& analogs } \\
t \text {-Test }^{\S} \text { : }\end{array}$ & $\begin{array}{l}0.1 \\
6.2\end{array}$ & $\begin{array}{l}0.06 \\
4.7\end{array}$ & 1.4 & $\begin{array}{l}0.2 \\
9.8\end{array}$ & $\begin{array}{l}0.2 \\
9.8\end{array}$ & 2.0 \\
\hline $\begin{array}{l}\text { OG } \\
\text { Preservatives \& analogs }\end{array}$ & $\begin{array}{l}-- \\
--\end{array}$ & $\begin{array}{l}p=0.001 \\
p=0.588\end{array}$ & $\begin{array}{l}-- \\
--\end{array}$ & $\begin{array}{l}-- \\
--\end{array}$ & $\begin{array}{l}p=1.0 \\
p=1.0\end{array}$ & $\begin{array}{l}-- \\
--\end{array}$ \\
\hline
\end{tabular}

* MIC: Minimum inhibitory concentration; MFC: Minimum fungicidal concentration; FICI: Fractional inhibitory concentration indices; FFCI: Fractional fungicidal concentration indices (See Additional File 1: Methods for calculations).

${ }^{\dagger}$ Compound was tested up to $6.4 \mathrm{mM}$. For calculation purpose, $12.8 \mathrm{mM}$ (doubling of 6.4 $\mathrm{mM}$ ) was used.

${ }^{*} 99.8 \%$ fungal death.

$\S$ Student's t-test for paired data, namely, mean MIC or MFC of each compound

(combined) vs. mean MIC or MFC of each compound (alone), was determined in OG and eight compounds [viz., six preservatives and two natural analogs of 4I3M (thymol, carvacrol)]. 
OG, showing four-fold enhancement in antifungal efficacy when combined with OG. For MFCs, co-application of OG with all eight compounds (six preservatives, thymol, carvacrol) resulted in indifference [Fractional Fungicidal Concentration Indices ( $\mathrm{FFCls})=2.0$; Table 1].

Therefore, we concluded that the effect of "OG+ preservative" co-application was chiefly enhancing compounds' growth inhibitory efficacy, but not heightening their fungicidality. $413 \mathrm{M}$ was the most interactive preservative to OG.

\section{I3M and cellular ion/redox homeostasis}

$413 \mathrm{M}$ (4-isopropyl-3-methylphenol) is a synthetic analog of the natural products thymol (2-isopropyl-5-methylphenol) and carvacrol (5-isopropyl-2-methylphenol). As with thymol and carvacrol, $413 \mathrm{M}$ has been developed as an antimicrobial preservative $[\mathbf{7}, \mathbf{8}]$, where the color/odor-neutral characteristic of $413 \mathrm{M}$ is more appealing to consumer perception. However, comparing to its natural analogs, molecular targets of $413 \mathrm{M}-$ were largely uncharacterized.

By using vacuolar $(v p h 2 \Delta, v m a 1 \Delta)$ and antioxidant $(\operatorname{sod} 2 \Delta$, sod $1 \Delta, g \operatorname{lr} 1 \Delta$, yap $1 \Delta$ ) mutants of the model fungus Saccharomyces cerevisiae, we previously observed thymol was involved in cellular ion and redox homeostasis in fungi [9]. Preliminary results confirmed that the synthetic compound had the same effect as that of the natural compounds, where vacuolar $($ vph2 $\Delta$, vma1 $\Delta)$ and cytosolic superoxide dismutase ( $\operatorname{sod} 1 \Delta)$ mutants were especially more susceptible to $4 \mathrm{I} 3 \mathrm{M}$ compared to other yeasts tested (Figure data not shown).

Therefore, we speculated that, like the natural analog thymol, $413 \mathrm{M}$ might also be involved in cellular ion (which links to xenobiotic detoxification [10]) and redox homeostasis. Phenolics function as deleterious redox cyclers against microbial cells, and thus prevent microbial growth by disrupting cellular redox homeostasis $[\mathbf{1 1}, 12]$. Consequently, fungi having deficiency in vacuolar/antioxidant systems, viz., abnormality in xenobiotic detoxification and antioxidation, would be more susceptible to $413 \mathrm{M}$.

\section{Overcoming fludioxonil tolerance of Aspergillus mu- tants by $4 \mathrm{I} 3 \mathrm{M}$}

The usefulness of $413 \mathrm{M}$ for overcoming fungicide tolerance was further investigated. The phenylpyrrole fungicide fludioxonil inhibits fungal growth by triggering excessive stimulation of signaling pathway, such as mitogen-activated protein kinase (MAPK) pathway [13]. This MAPK pathway is responsive to oxidative cues, thus protects fungi from environmental oxidative stressors. However, fungi having mutations in MAPK genes escape fludioxonil toxicity, resulting in development of fludioxonil tolerance [13].

We included the WT and two oxidative signaling MAPK mutants (sakA $\Delta, m p k C \Delta$ ) of Aspergillus fumigatus for this study, considering the mechanisms of MAPK signaling were well characterized in this species $[\mathbf{1 4}, \mathbf{1 5}]$. As shown in Figure 1, the growth of A. fumigatus WT was completely inhibited by
$50 \mu \mathrm{M}$ fludioxonil, while MAPK mutants exhibited tolerance to fludioxonil (Additional file 1: Methods). However, 4I3M effectively overcame fungal fludoxonil tolerance, where coapplication of sub-inhibitory concentration of $413 \mathrm{M}(0.6 \mathrm{mM})$ with fludioxonil completely inhibited the escape of MAPK mutants from fludioxonil toxicity.

Noteworthy is that, with independent treatment of $413 \mathrm{M}$, sakA $\triangle$ and $m p k C \Delta$ antioxidant mutants developed less radial growth (viz., more sensitive to 4I3M) compared to WT (Figure 1). Thus, in accordance with yeast bioassay (See above), results further indicated 4I3M negatively affected fungal redox homeostasis, where antioxidant MAPK mutants having deficiency in oxidative stress defense were more susceptible to $413 \mathrm{M}$. We further surmised that higher susceptibility to $4 \mid 3 \mathrm{M}$ could be one contributing mechanism of overcoming fludioxonil tolerance of MAPK mutants.

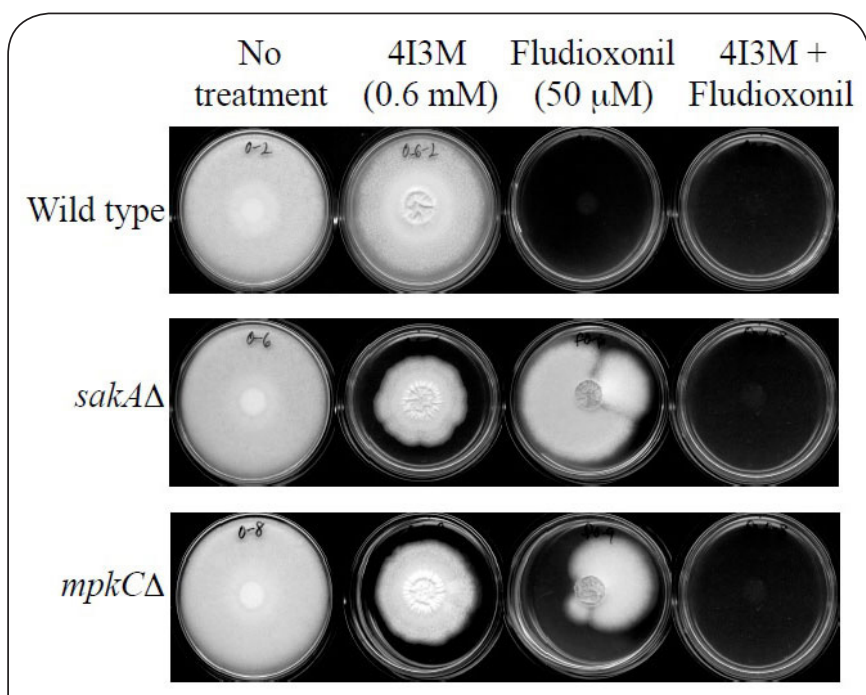

Figure 1. Overcoming fludioxonil tolerance of $A$. fumigatus MAPK mutants (sakA $\Delta, m p k C \Delta)$ by $4 \mathrm{I} 3 \mathrm{M}$.

Compatibility of $4 \mathrm{I} 3 \mathrm{M}$ and its natural derivatives with commercial surfactants: Compound-surfactant specificity Ingredients' compatibility is essential for the functionality of antifungal agents in preservative formulation. For example, surfactants (Surface Active Agents) are amphiphilic organic agents, which lower surface tension of liquids in many industrial products, thus enabling emulsification or compound delivery easier [16]. While surfactants do not have to possess antimicrobial activities per se, they could adversely affect the functionality of active ingredients depending on types of surfactant formulation. To further assess $4 \mathrm{I}_{3} \mathrm{M}$ 's antifungal efficacy in formulation, compatibility of $413 \mathrm{M}$ (and its natural derivatives thymol and carvacrol for comparison) with three commercial surfactants was investigated by determining MICs and MFCs (Additional File 1: Methods). For MICs, no fungal growth was detected during liquid incubation (viz., 10\% 
Kim et al. Microbiology Discovery 2016,

surfactant solution in water; $48 \mathrm{hrs}, 168 \mathrm{hrs}$ ) even w/o incorporation of $413 \mathrm{M}$ or derivatives into three surfactant solutions.

However, for MFCs, two different fungal responses were detected depending on types of surfactants. With surfactant 1 [ $C_{12-14}$ fatty alcohol polyglycol ether-based; Trade name: Genapol ( $\mathrm{pH} 7.4$ ) (See Additional File 1: Methods)], 5 to 6\% fungal recovery was initially determined in control plates (viz., w/o 4I3M or its derivatives; both 48 and 168 hrs) (Figure 2). However, incorporation of $4 \mathrm{I3M}$ or derivatives (12.8 to 51.2 $\mathrm{mM}$ ) into surfactant 1 resulted in notable increase in fungal recovery (viz., enhanced fungal growth; Figure 2 ), indicating surfactant 1 negatively affected the antifungal function of $4 \mathrm{I} \mathrm{M}$ or its derivatives.

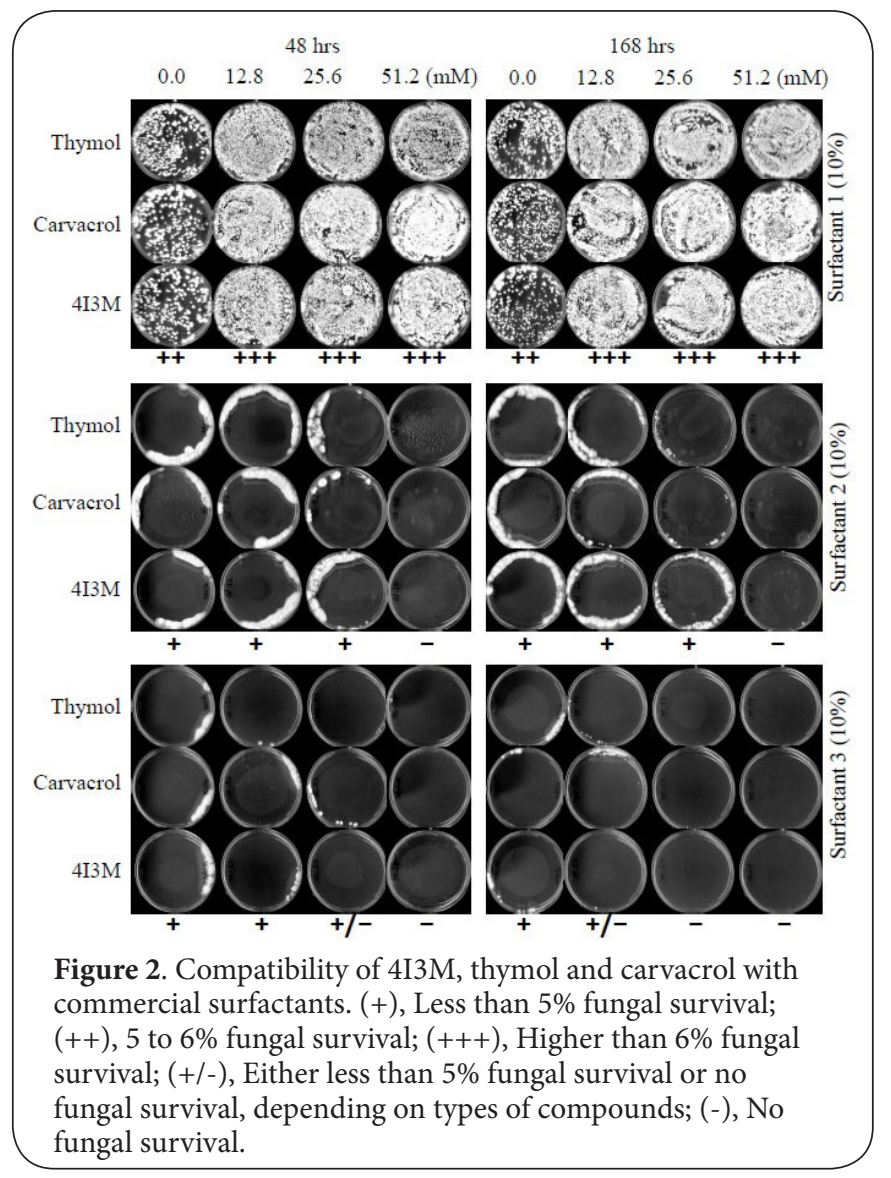

In contrast, the other two surfactants, i.e., surfactant $2\left[\mathrm{C}_{8-16}\right.$ fatty alcohol (alkyl polyglucosides)-based; Trade name: Glucopon (pH 7.6)] and surfactant 3 [sodium lauryl sulfate-based; Trade name: Stepanol ( $\mathrm{pH} 7.7)$ ], interacted positively with $413 \mathrm{M}$ or its derivatives for antifungal activity, where co-application of 4I3M/ derivatives (up to $51.2 \mathrm{mM}$ ) with surfactant 2 or 3 achieved complete inhibition of fungal growth (both 48 and 168 hrs; Figure 2). Of note, surfactant 2 or 3 , alone, possessed potent antifungal activity, where only peripheral fungal growth was detected on recovery plates even without incorporation of
$4 \mathrm{I3M}$ /derivatives (Figure 2). Higher concentration (viz., 25.6 to $51.2 \mathrm{mM}$ ) of $413 \mathrm{M} /$ derivatives achieved enhanced antifungal efficacy (48 or $168 \mathrm{hrs}$ ).

It is noteworthy that, although both surfactants 1 and 2 were fatty alcohol-based products, they exhibited completely opposite specificity to $413 \mathrm{M}$ or its derivatives (resultantly, opposite antifungal efficacy; See above). While determining precise mechanism of differential specificity is necessary, we speculated additional ingredients that might reside in (commercial) surfactants could also contribute to the differential specificity. To further our understanding of $413 \mathrm{M} /$ derivatives compatibility with conventional surfactants, comprehensive research by including additional numbers of surfactants (viz., four different types: anionic, cationic, nonionic, amphoteric) is currently underway.

Collectively, characteristics of surfactants, including intrinsic antifungal activity, antagonism (shown above), etc., are important parameters, and thus, should be well-elucidated when developing sustainable antifungal formulation.

\section{Conclusions}

In this study, antifungal efficacy of GRAS compounds and conventional preservatives was investigated against model yeast and Aspergillus. The selected compounds OG and 4I3M, alone or in combination, effectively prevented fungal growth, where $413 \mathrm{M}$ could also overcome fludioxonil tolerance of Aspergillus mutants. Application of adequate surfactants was crucial for achieving optimum antifungal activity of compounds, thus emphasizing the importance of compound-compound or compound-surfactant specificity during the development of sustainable antifungal agents.

\section{Additional files}

\section{Additional File 1: Methods}

\section{List of abbreviations}

4I3M: 4-Isopropyl-3-methylphenol

CFU: Colony Forming Units

CLSI: Clinical Laboratory Standards Institute

FDA: Food and Drug Administration

FFCl: Fractional Fungicidal Concentration Index

FICl: Fractional Inhibitory Concentration Index

GRAS: Generally Regarded As Safe

MAPK: Mitogen-Activated Protein Kinase

MFC: Minimum Fungicidal Concentration

MIC: Minimum Inhibitory Concentration

OG: Octyl gallate

WT: Wild type

\section{Competing interests}

The authors declare that they have no competing interests. 
Kim et al. Microbiology Discovery 2016,

Authors' contributions

\begin{tabular}{|l|c|c|c|c|c|c|}
\hline Authors' contributions & JHK & WHC & KLC & LWC & WJO & KJ \\
\hline Research concept and design & $\checkmark$ & $\checkmark$ & -- & -- & -- & -- \\
\hline $\begin{array}{l}\text { Collection and/or assembly of } \\
\text { data }\end{array}$ & $\checkmark$ & -- & $\checkmark$ & -- & -- & -- \\
\hline Data analysis and interpretation & $\checkmark$ & $\checkmark$ & $\checkmark$ & $\checkmark$ & $\checkmark$ & $\checkmark$ \\
\hline Writing the article & $\checkmark$ & -- & -- & -- & -- & -- \\
\hline Critical revision of the article & $\checkmark$ & $\checkmark$ & $\checkmark$ & $\checkmark$ & $\checkmark$ & $\checkmark$ \\
\hline Final approval of article & -- & -- & -- & $\checkmark$ & -- & -- \\
\hline Statistical analysis & $\checkmark$ & -- & -- & -- & -- & -- \\
\hline
\end{tabular}

Acknowledgement

This research was conducted under USDA-ARS CRIS Project 2030-42000-039-00.

Publication history

Editor: Abdul Hamood, Texas Tech University Health Sciences Center, USA.

Received: 30-Sep-2016 Final Revised: 21-Nov-2016

Accepted: 12-Dec-2016 Published: 21-Dec-2016

\section{References}

1. Denning DW. Invasive aspergillosis. Clin Infect Dis. 1998; 26:781-803. | Article I PubMed

2. Campbell BC, Molyneux RJ and Schatzki TF. Current research on reducing pre- and post-harvest aflatoxin contamination of US almond, pistachio and walnut. J Toxicol Toxin Rev. 2003; 22:225-66. | Article

3. Manikandan P, Varga J, Kocsube S, Revathi R, Anita R, Doczi I, Nemeth TM, Narendran V, Vagvolgyi C, Bhaskar M, Manoharan C, Samson RA and Kredics L. Keratitis caused by the recently described new species Aspergillus brasiliensis: two case reports. J Med Case Rep. 2010; 4:68. Article | PubMed Abstract | PubMed FullText

4. Moser $\mathrm{CL}$ and Meyer BK. Comparison of compendial antimicrobial effectiveness tests: a review. AAPS PharmSciTech. 2011; 12:222-6. | Article | PubMed Abstract | PubMed FullText

5. Freiesleben $\mathrm{SH}$ and Jäger AK. Correlation between plant secondary metabolites and their antifungal mechanisms - A review. Med Aromat Plants. 2014; 3:154. I Article

6. Li MH. Effects of nonionic and ionic surfactants on survival, oxidative stress, and cholinesterase activity of planarian. Chemosphere. 2008; 70:1796-803. | Article | PubMed

7. Choi WS, Jang SH, Jang DY, Choi KG, Lee BH, Kim TJ and Jung BJ. Antifungal activities for derivatives of 4-isopropyl-3-methylphenol and 5-isopropyl-3-methylphenol against plant pathogenic fungi. Korean J Pest Sci. 2006; 10:249-61. | Article

8. Axe A and Bradshaw D. Antibacterial composition comprising 4-isopropyl-3-methylphenol and zinc ions. United States Patent Application Publication Pub. No. 20120039820. 2012.

9. Kim JH, Chan KL, Faria NC, Martins Mde L and Campbell BC. Targeting the oxidative stress response system of fungi with redox-potent chemosensitizing agents. Front Microbiol. 2012; 3:88. | Article | PubMed Abstract | PubMed FullText

10. Rutledge RM, Ghislain M, Mullins JM, de Thozee CP and Golin J. Pdr5mediated multidrug resistance requires the CPY-vacuolar sorting protein Vps3: are xenobiotic compounds routed from the vacuole to plasma membrane transporters for efflux? Mol Genet Genomics. 2008; 279:573-83. | Article | PubMed

11. Guillen F and Evans CS. Anisaldehyde and veratraldehyde acting as redox cycling agents for $\mathrm{H}(2) \mathrm{O}(2)$ production by pleurotus eryngii. Appl Environ Microbiol. 1994; 60:2811-7. | Article | PubMed Abstract | PubMed FullText

12. Jacob C. A scent of therapy: pharmacological implications of natural products containing redox-active sulfur atoms. Nat Prod Rep. 2006 23:851-63. | Article | PubMed

13. Kojima K, Takano Y, Yoshimi A, Tanaka C, Kikuchi T and Okuno T. Fungicide activity through activation of a fungal signalling pathway. $\mathrm{Mol}$ Microbiol. 2004; 53:1785-96. | Article | PubMed

14. Xue T, Nguyen CK, Romans A and May GS. A mitogen-activated protein kinase that senses nitrogen regulates conidial germination and growth in Aspergillus fumigatus. Eukaryot Cell. 2004; 3:557-60. | Article | PubMed Abstract | PubMed FullText

15. Reyes G, Romans A, Nguyen CK and May GS. Novel mitogen-activated protein kinase MpkC of Aspergillus fumigatus is required for utilization of polyalcohol sugars. Eukaryot Cell. 2006; 5:1934-40. | Article | PubMed Abstract | PubMed FullText

16. Raffa P, Wever DA, Picchioni F and Broekhuis AA. Polymeric surfactants: synthesis, properties, and links to applications. Chem Rev. 2015; 115:8504-63. | Article | PubMed

17. U.S. Food and Drug Administration (FDA). Everything Added to Food in the United States. 2011. I Website

18. Clinical and Laboratory Standards Institute (CLSI). Reference Method for Broth Dilution Antifungal Susceptibility Testing of Filamentous Fungi: Approved Standard-Second Edition. CLSI document M38-A2; Clinical and Laboratory Standards Institute: Wayne, PA, USA.2008.

19. Saccharomyces cerevisiae Genome Database. 2016. I Website

20. Meletiadis J, Antachopoulos C, Stergiopoulou T, Pournaras S, Roilides E and Walsh TJ. Differential fungicidal activities of amphotericin B and voriconazole against Aspergillus species determined by microbroth methodology. Antimicrob Agents Chemother. 2007; 51:3329-37. | Article | PubMed Abstract | PubMed FullText

21. Isenberg HD. Clinical Microbiology Procedures Handbook. 1st Ed. Washington, DC: American Society for Microbiology. 1992.

22. Odds FC. Synergy, antagonism, and what the chequerboard puts between them. J Antimicrob Chemother. 2003; 52:1. I Article I PubMed

23. Kirkman TW. Statistics to use. 2016. | Website

Citation:

Kim JH, Hart-Cooper W, Chan KL, Cheng LW, Orts WJ and Johnson K. Antifungal efficacy of octylgallate and 4-isopropyl-3-methylphenol for control of Aspergillus. Microbiol Discov. 2016; 4:2.

http://dx.doi.org/10.7243/2052-6180-4-2 